\title{
Surgical Treatment of Lower Cervical Locked Facet. An Experience in 20 Cases
}

\author{
Wael A. Hammad*, Bokhary Mahmoud \\ Al-Azhar University, Cairo, Egypt \\ Email: *waelhammad78@yahoo.com
}

How to cite this paper: Hammad, W.A. and Mahmoud, B. (2019) Surgical Treatment of Lower Cervical Locked Facet. An Experience in 20 Cases. Open Journal of Modern Neurosurgery, 9, 302-313. https://doi.org/10.4236/ojmn.2019.93029

Received: May 16, 2019

Accepted: July 2, 2019

Published: July 5, 2019

Copyright $\odot 2019$ by author(s) and Scientific Research Publishing Inc. This work is licensed under the Creative Commons Attribution International License (CC BY 4.0).

http://creativecommons.org/licenses/by/4.0/

(c) (i) Open Access

\begin{abstract}
Background: Cervical spine injuries are common as a result of a growing number of high energy accidents. The subaxial Injury Classification System and Severity Score (SLICS) suggest that a unilateral or bilateral facet dislocation must be managed surgically, even in the absence of SCI (Level of Evidence III). The surgical approaches could be anterior, posterior or combined anterior and posterior approaches. Methods: 20 patients, 12 males and 8 females, with age ranged from 20 to 45 years with lower cervical spine locked facet treated operatively by anterior or posterior spinal instrumentation after trial of closed reduction by skull traction. Results: In this series, satisfactory closed reduction was achieved in 15 patients with percentage $75 \%$ and fixed anteriorly, but 5 patients with percentage $25 \%$ needed posterior approach for reduction. Regarding ASIA score all of the patients improved at least one level after surgery except 2 cases with preoperative score A: they didn't improve. Mean preoperative pain score VAS was 7.7 (range from 5 to 9) and postoperative mean of VAS was 0.75 with range from 0 to 3 until final follow up. Conclusion: Anterior approach with discectomy and fusion is necessary; however, if the closed reduction failed, posterior open reduction is indicated with lateral mass fixation, combined approaches can be indicated in specific cases such as increase of the kyphotic angle post anterior approach or when an osteotomy may be required to restore cervical alignment and neural decompression.
\end{abstract}

\section{Keywords}

Cervical Locked Facet, Facet Dislocation, Cervical Spine Injury

\section{Introduction}

Cervical spine injuries are common as a result of a growing number of high energy accidents. Surgical treatment of subaxial cervical spine injuries is impor- 
tant for restoration and protection of the spinal cord and nerve roots, re-establishing cervical alignment and also to restore spinal stability [1].

Cervical facet fractures and dislocation represent approximately $6 \%$ of all cervical spine fractures. The clinical spectrum of these injuries ranges from patient being neurologically intact to complete neurological deficits. They can be unilateral or bilateral and may be associated with subluxation or dislocation. The unilateral facet dislocation is produced by flexion, lateral tilt, and rotation; while bilateral dislocations produced by flexion, axial loading, and anterior shear stress forces. The facets are subluxated when there is some contact between the two articular surfaces of the facet joint; while in dislocation, there is no residual contact. The most common site of facet injuries is C5-C6 (25\% - 60\%), followed by C6-C7 (25\% - 30\%) [2] [3].

The delay before spinal decompression has been the subject of debate and ultimate neurological outcome may be affected by both patient variables (age, sex, medical status, and presence of other injuries) and by management variables (early reduction, steroids, blood pressure management). Cord edema, hypoxia, and ischemia within a constitutionally narrowed vertebral canal can also contribute further to secondary cord damage [4] [5] [6].

A combination of lower height, smaller anteroposterior diameter of the superior facet, and a more horizontally oriented superior facet at C6 and C7 levels in vivo may explain the predilection of this level for locked facet injury more than other levels [7].

MRI is generally recommended that a pre-reduction MRI is prudent to get an understanding of the status of the spinal cord and any potentially offending soft tissue or bony structures placing the spinal cord at risk [8].

Cervical facet joint dislocation is generally managed surgically and the Subaxial Injury Classification System and Severity Score (SLICS) suggest that a unilateral or bilateral facet dislocation must be managed surgically, even in the absence of SCI (Level of Evidence: III) [9] [10] [11].

Conservative management is associated with a high incidence of recurrent instability and long-term pain and disability (Level of Evidence: III). Thus, surgical fixation has become increasingly favored for unilateral facet lesions, particularly those that are displaced (Level of Evidence III). In patients with cervical dislocations, early closed traction may play a role in the treatment, since up to $70 \%$ of the dislocations can thereby be reduced with external traction (Level of Evidence: III) [12] [13] [14].

The surgical approaches to these types of injury could be anterior, posterior or combined anterior and posterior approaches and this should be individualized according to the case.

Anterior cervical fusion procedures were associated with less frequent failure to maintain reduction (10 [5\%] of 213 patients) when compared with posterior cervical fusion procedures (38 [14\%] of 280 patients) among all patients with subaxial cervical injuries treated operatively [15] [16] [17]. 
In anterior approach after disk and posterior ligament resection, distractor pins are inserted. Distractor placement results in local kyphosis, unlocking the posterior facet joints with some additional posterior force applied to the vertebral body. In unilateral dislocation, the pins are placed in a similar fashion but with additional coronal separation to open room for rotation. After distraction, which may release the facet joints, some gentle posterior force may be applied in the rostral vertebral body, reducing the locked joint and recovering articular congruence, an alternative maneuver for reducing a locked facet joint is continuous intraoperative external cranial traction. After disc removal, the use of a Cobb elevator in the interbody space can also be utilized to move away the dislocated facets, making the reduction easier. Most of the time, anterior cervical discectomy and interbody fusion are sufficient to remove the disk fragment present in the canal, even when some caudal or cranial migration is present.

If the dislocation could not be reduced after an anterior approach, the patient must be turned prone with a direct partial facetectomy, reduction and subsequent posterior fixation. An additional anterior procedure may offer a stronger fixation in such cases and should be considered at the surgeon's discretion, potentially restoring the loss of disc space and maintaining some degree of cervical lordosis.

Posterior approaches based on rigid fixation techniques with lateral mass screws or pedicular screws are a good alternative for treating distractive and rotation injuries using reduction maneuvers that can be applied directly to realign the spine. Additionally, patients with posterior bone compression associated with facet dislocation, such as a lamina fragment into the canal, can be managed successfully using a posterior approach.

The combined approach provides the strongest fixation, significantly limiting motion and increases the fusion rate, although without the additional advantage for neurological recovery.

The objective of this study to represent our experience in cases with lower locked cervical facet and discussion the optimum treatment of this type of injury.

\section{Subject and Method}

Between January 2013 and December 2016, 20 patients diagnosed and managed at Aseer central hospital, KSA, 12 males and 8 females, with age ranged from 20 to 45 years with lower cervical spine locked facet injury treated operatively by anterior or posterior spinal instrumentation after trial of closed reduction by skull traction.

The selection criteria in this study were lower cervical spine locked facet injury either unilateral or bilateral locked facet, for that upper cervical locked facet injury was excluded, and other types of cervical spine injury excluded also.

On admission all patients had plain X ray cervical spines (anteroposterior and lateral, and oblique views), CT scan and MR imaging also done for all our patients. 
Complete and detailed neurological examination was done both preoperative and post-operative and at time of discharge using the Frankel motor score system. The duration of follow-up ranged from 12 to 18 months. At each visit, all patients submitted for X-ray spine AP and Lateral and complete neurological assessment using Frankel motor score system were done.

\section{Closed Reduction Technique}

We did closed reduction early in the first 24 hours after MRI imaging in cases with neurological deficit to rule out disc herniation, the initial weight was $2.5 \mathrm{~kg}$ per injury level. The traction was in neutral, flexion or extension position, according to injury type.

The patients followed clinically and radiologically (with lateral cervical radiography performed in the bed) until reduction is obtained. Traction at any point of time whenever there is evidence of distraction of $>10 \mathrm{~mm}$ between the affected spine segments. Bilateral facet dislocations reduce more commonly than unilateral dislocations. Our main purpose of traction is to obtain and maintain closed reduction in lateral cervical spine radiography. The technique was done with the patient in a supine neutral position and infiltration of lidocaine at pin site penetration after betadine scrubbing; we did most of cases in an intensive care unit with a specific bed for traction. The pins then positioned just below the superior temporal line, to avoid the temporalis muscle and the temporal artery. We did flexion and contra lateral rotation in some patients with unilateral facet dislocation.

\section{Follow-Up Data}

Post-operative AP and lateral x-ray films were done and patients were advised to start mobilization while wearing neck collar, drain usually removed 48 hours after surgery, neck support were generally worn for one month post-operative. Follow up evaluation including neurological assessment by ASIA score system. Standing, or upright AP and lateral radiography were scheduled at 1.5, 3, 6, and 12 months and annually thereafter. The duration of follow-up was ranged from 9 to 18 months. Comparison of the neurological state pre and postoperative of these patients using ASIA score and VAS was done and analyzed statistically.

\section{Results}

The total Numbers of patients was 20 with mean age 31.5 years ranged from 22 to 43 years the patients were 14 males, and 6 females (Figure 1). The level of facet dislocation was C4-5 in four, C5-6 in six, C6-7 in eight and C7-T1 in two patients (Figure 2). Translation distance ranged from 4 to $8 \mathrm{~mm}$ with mean 5.95 $\mathrm{mm}$. Regarding ASIA score, all patients improved at least one level after surgery except 2 cases with preoperative score A didn't improve. Mean preoperative pain score VAS was 7.7 (range from 5 to 9 ) and postoperative mean of VAS is 0.75 with (range from 0 to 3 ) until final follow up period (Figure 3). Anterior de- 
compression and instrumented fusion (ACDF) was done in 14 patients with percentage $70 \%$ of cases. This was the method mostly used, posterior fusion done in 5 patients with percentage $25 \%$ cases and the combined anterior and posterior approach done in one patient with percentage $5 \%$ started with anterior approach and on follow up the kyphotic angle increased so we did for him posterior instrumentation as a second session. Satisfactory closed reduction was achieved in 15 patients of all cases with percentage of $75 \%$. Bilateral locked facet has successful reduction in 10 cases from 12 cases with percentage 83\%, however in cases with unilateral locked facet successful reduction was done in 5 cases from 8 with percentage of $62 \% .5$ patients with percentage $25 \%$ needed posterior approach for reduction.

\section{Summary of Complications and Mortality}

We had surgery related complications in 2 cases (Table 1 ). The first complication in (Case 3) was increase of kyphotic angel during follow up period and treated by augmentation of the fixation by posterior instrumentation. The second one in (Case 15) was transient dysphagia, managed conservatively with insertion of nasogastric tube.

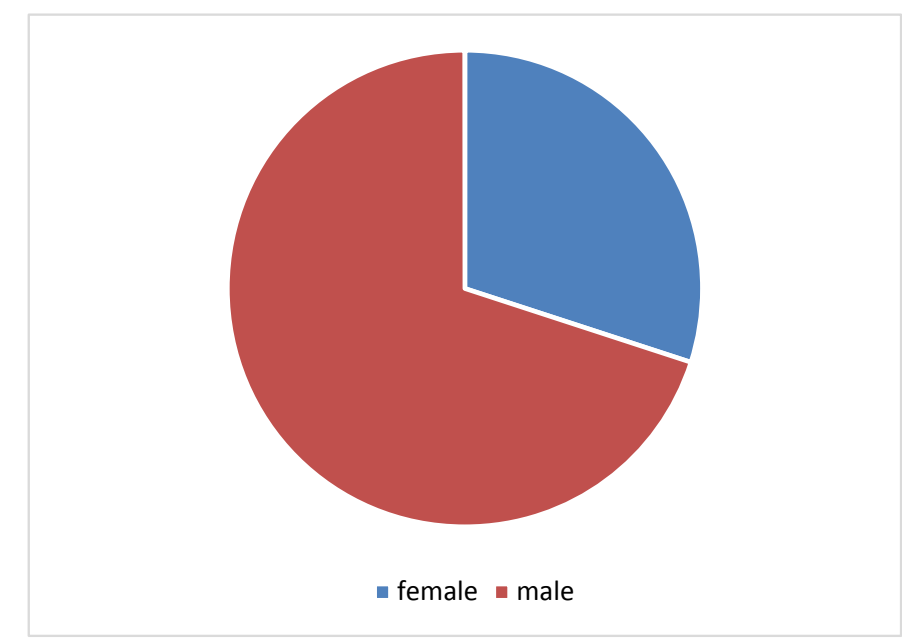

Figure 1. Sex distribution.

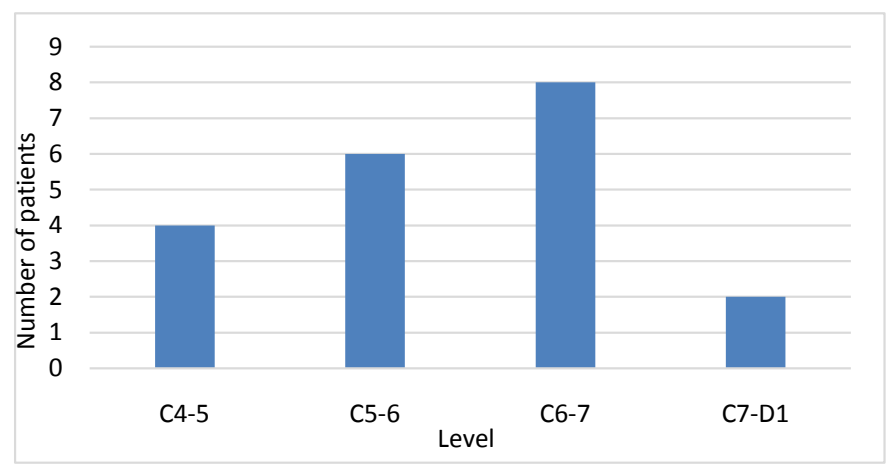

Figure 2. Level of facet dislocation. 


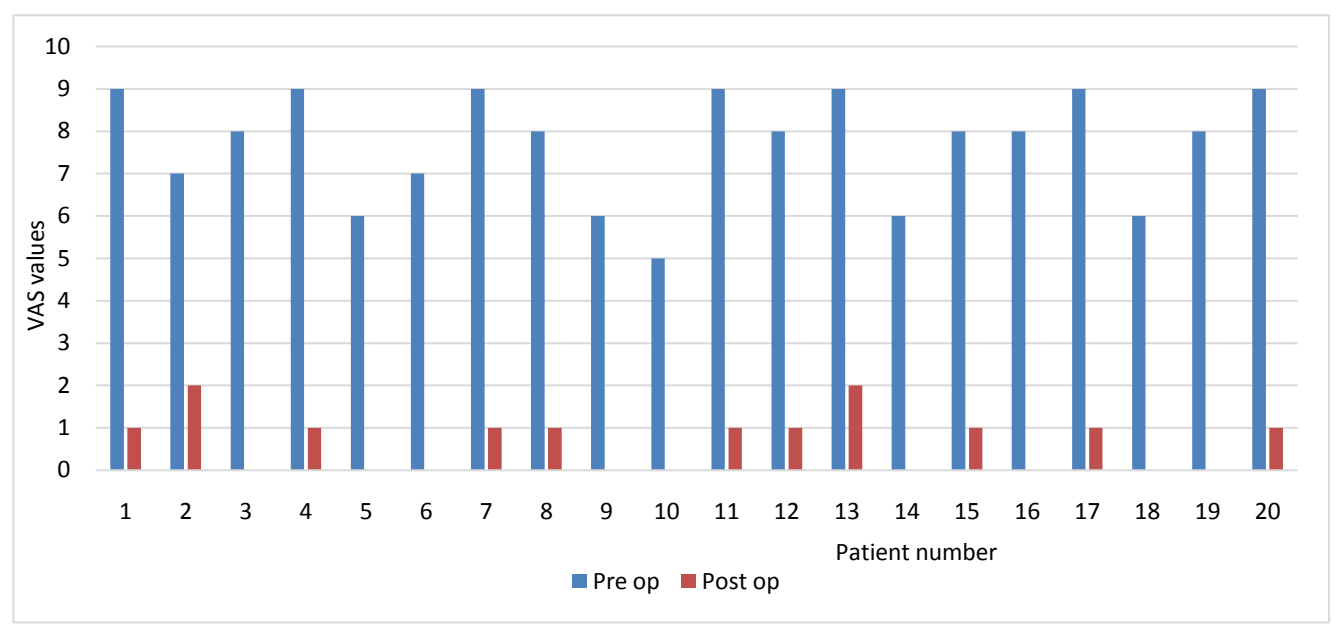

Figure 3. Pre and post operative VAS values.

Table 1. Demographics and clinical data.

\begin{tabular}{|c|c|c|c|c|c|c|c|c|c|c|c|c|c|}
\hline \multirow{2}{*}{$\begin{array}{c}\text { Patients } \\
1\end{array}$} & \multirow{2}{*}{$\begin{array}{r}\text { Age } \\
34\end{array}$} & \multirow{2}{*}{$\begin{array}{c}\text { Gender } \\
\text { F }\end{array}$} & \multirow{2}{*}{$\begin{array}{l}\text { Level } \\
\text { C5-6 }\end{array}$} & \multicolumn{2}{|c|}{$\begin{array}{c}\text { ASIA Score } \\
\text { Pre op post op }\end{array}$} & \multirow{2}{*}{$\begin{array}{c}\begin{array}{c}\text { Translation } \\
\text { distance } \\
(\mathrm{mm})\end{array} \\
6\end{array}$} & \multirow{2}{*}{$\begin{array}{c}\begin{array}{c}\text { Surgical } \\
\text { approach }\end{array} \\
\text { Ant }\end{array}$} & \multirow{2}{*}{$\begin{array}{c}\begin{array}{c}\text { Success of } \\
\text { closed } \\
\text { Reduction }\end{array} \\
+\end{array}$} & \multicolumn{2}{|c|}{$\begin{array}{c}\text { VAS } \\
\text { Pre op } \\
\text { post op }\end{array}$} & \multirow{2}{*}{$\begin{array}{c}\begin{array}{c}\text { Facet } \\
\text { dislocation }\end{array} \\
\text { Unilateral }\end{array}$} & \multirow{2}{*}{$\begin{array}{c}\begin{array}{c}\text { Follow up } \\
\text { months }\end{array} \\
12\end{array}$} & \multirow{2}{*}{$\begin{array}{c}\text { Morbidity/ } \\
\text { Mortality } \\
-\end{array}$} \\
\hline & & & & $\mathrm{E}$ & $\mathrm{E}$ & & & & 9 & 1 & & & \\
\hline 2 & 40 & M & C6-7 & $\mathrm{E}$ & $\mathrm{E}$ & 5 & Ant & + & 7 & 2 & bilateral & 9 & _- \\
\hline 3 & 26 & $\mathrm{~F}$ & C6-7 & $\mathrm{D}$ & $\mathrm{E}$ & 6 & Combined & + & 8 & 0 & unilateral & 18 & Kyphotic angel \\
\hline 4 & 30 & M & $\mathrm{C} 5-6$ & E & $\mathrm{E}$ & 5 & Ant & + & 9 & 3 & bilateral & 18 & - \\
\hline 5 & 26 & M & $\mathrm{C} 4-5$ & $\mathrm{D}$ & $\mathrm{E}$ & 7 & Ant & + & 6 & 0 & bilateral & 9 & - \\
\hline 6 & 41 & M & C6-7 & $\mathrm{E}$ & $\mathrm{E}$ & 5 & post & _ & 7 & 0 & unilateral & 12 & - \\
\hline 7 & 26 & M & C7-T1 & A & A & 7 & Post & _ & 9 & 1 & bilateral & 12 & Pneumonia \\
\hline 8 & 33 & $\mathrm{~F}$ & C5-6 & $\mathrm{D}$ & $\mathrm{E}$ & 5 & Ant & + & 8 & 1 & unilateral & 18 & _- \\
\hline 9 & 30 & M & C4-5 & B & B & 7 & Ant & + & 6 & 0 & bilateral & 18 & $\begin{array}{l}\text { Pulmonary } \\
\text { embolism }\end{array}$ \\
\hline 10 & 32 & M & C6-7 & $\mathrm{C}$ & $\mathrm{E}$ & 4 & Ant & + & 5 & 0 & bilateral & 12 & - \\
\hline 11 & 37 & $\mathrm{~F}$ & C5-6 & $\mathrm{C}$ & $\mathrm{D}$ & 8 & Ant & + & 9 & 1 & bilateral & 9 & - \\
\hline 12 & 27 & $\mathrm{~F}$ & C5-6 & C & $\mathrm{E}$ & 6 & Post & _ & 8 & 1 & unilateral & 9 & _ \\
\hline 13 & 34 & M & C6-7 & A & A & 6 & post & - & 9 & 2 & bilateral & died & died \\
\hline 14 & 43 & M & C7-T1 & C & $\mathrm{E}$ & 7 & Ant & + & 6 & 0 & bilateral & 18 & _- \\
\hline 15 & 25 & M & C4-5 & $\mathrm{E}$ & $\mathrm{E}$ & 5 & Ant & + & 8 & 1 & unilateral & 12 & $\begin{array}{l}\text { Transient } \\
\text { dysphagia }\end{array}$ \\
\hline 16 & 31 & $\mathrm{~F}$ & C5-6 & $\mathrm{D}$ & E & 6 & Ant & + & 8 & 0 & unilateral & 9 & - \\
\hline 17 & 25 & M & C6-7 & $\mathrm{E}$ & $\mathrm{E}$ & 7 & Ant & + & 9 & 1 & bilateral & 18 & - \\
\hline 18 & 29 & M & C4-5 & $\mathrm{D}$ & $\mathrm{E}$ & 5 & Post & - & 6 & 0 & unilateral & 12 & \\
\hline 19 & 39 & M & C6-7 & $\mathrm{C}$ & $\mathrm{D}$ & 6 & Ant & + & 8 & 0 & bilateral & 18 & _ \\
\hline 20 & 22 & M & C6-7 & $\mathrm{E}$ & $\mathrm{E}$ & 6 & Ant & + & 9 & 1 & bilateral & 18 & _ \\
\hline
\end{tabular}


Also we had two medical complications in our cases (Table 1). The first one in (Case 7) was pneumonia treated by systemic antibiotics, and the second in (Case 9) was pulmonary embolism treated by anticoagulants.

One Case (13) presenting 5\% of all cases died two weeks post surgery and the patient was in respiratory failure before surgery.

\section{Case Presentation}

\section{Patient 5:}

Male patient 26 years old fell from height with C4-5 bilateral facet dislocation, pre-operative VAS 6 and ASIA score D, anterior approach with discectomy of C4-5 and C5-6 with cages and anterior plate after reduction was done (Figures 4-6). The patient improved post operatively to ASIA score E, and VAS 0, discharged from the hospital 7 days after surgery without complications.

\section{Patient 13:}

Male patient 34 years old involved in RTA with C6-7 bilateral facet dislocation, pre-operative ASIA score was A, and VAS was 9 with respiratory failure so intubated and ventilated. MRI showed cord contusion (Figure $7(\mathrm{c})$ ), closed reduction failed, operated by posterior approach with open reduction and lateral mass instrumentation done (Figure 7 and Figure 8), Post operatively the patient did not improve and died after two weeks of surgery.

\section{Patient 16:}

A female patient 31 years old involved in RTA with unilateral C5-6 facet dislocation pre operative ASIA score was D, VAS was 8. She was operated anteriorly after closed reduction (Figure 9 and Figure 10) She improved post operatively to ASIA score E, kyphotic angel to $-2^{\circ}$ and VAS 0 and discharged from the hospital 5 days after surgery without complications.

\section{Discussion}

A locked facet injury of the cervical spine is a result of flexion-distraction type of injury [18]. This mechanism of injury makes the inferior facet of the rostral vertebra slip forward and over the superior facet of the caudal vertebra, and this can occur unilaterally or bilaterally. Treatment of this condition requires reduction and stabilization. Reduction can be accomplished by closed or open means. Wolf et al. reported that the success rate of closed reduction is higher for bilateral locked facets in comparison to the unilateral ones [19]. In our series we found also that the success rate of closed reduction is higher for bilateral locked facets with percentage $83 \%$ in comparison to the unilateral ones with percentage $62 \%$ of success rate.

In our series, we found that anterior approach was appropriate after successful closed skull traction success in patients with bilateral and unilateral locked facet dislocation (Table 1). However the posterior approach was appropriate for those patients with failure of closed reduction. Some surgeons suggested an open anterior and or posterior fixation with fusion without closed reduction [8] but we 
thought that closed reduction preoperative can guide you in planning to select one approach either anterior or posterior before surgery.

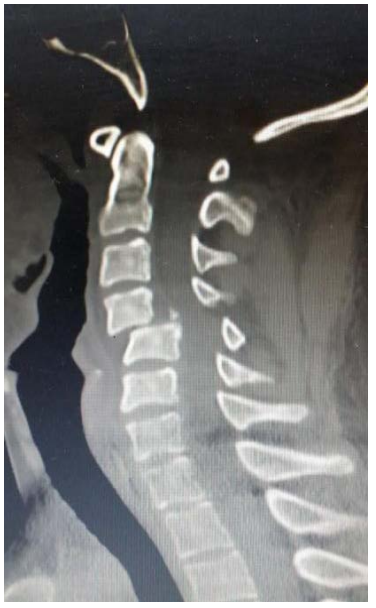

(a)

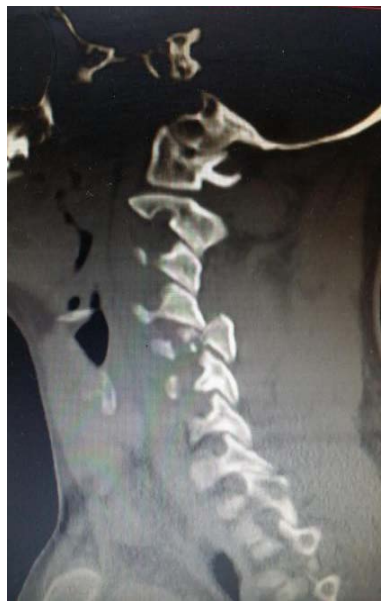

(b)

Figure 4. Pre-operative CT scan spine sagitalviews.

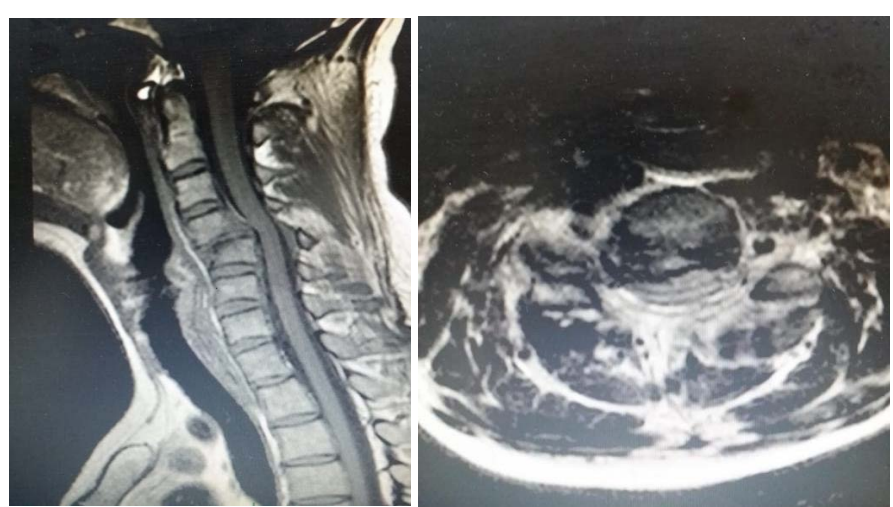

(a)

(b)

Figure 5. Pre operative MRI spine sagital (a) and axial (b) views.

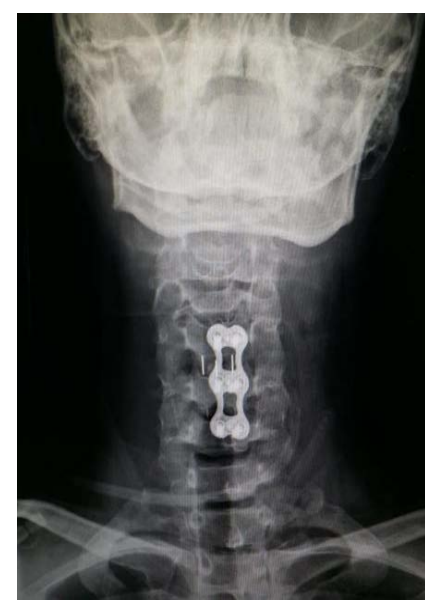

(a)

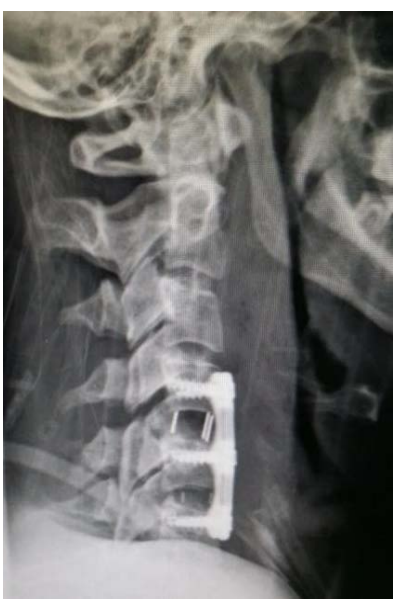

(b)

Figure 6. Post operative X ray AP (a) and lateral (b) views. 


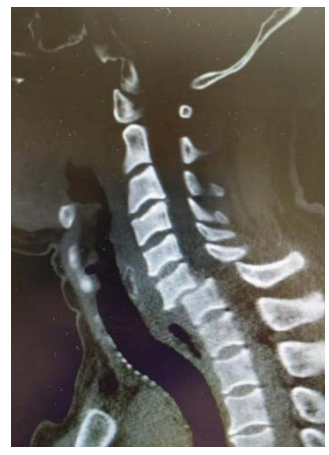

(a)

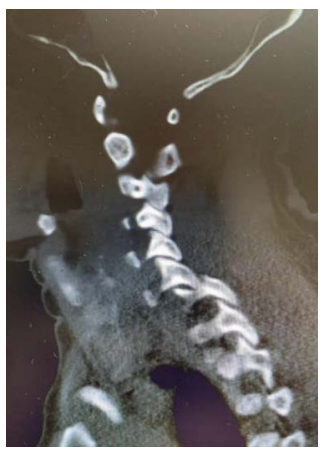

(b)

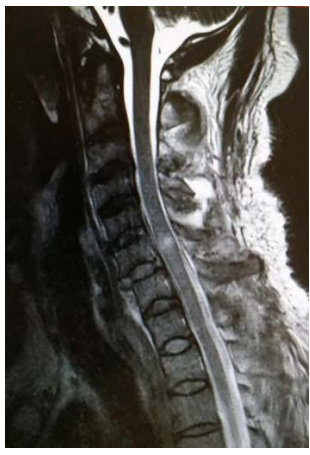

(c)

Figure 7. Pre operative CT spine sagital (a) and (b) views and sagital T2 MRI (c).

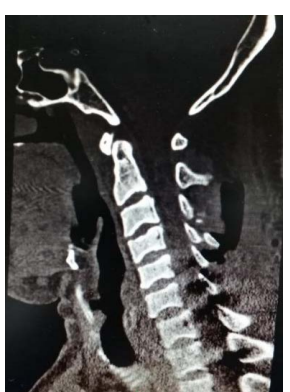

(a)

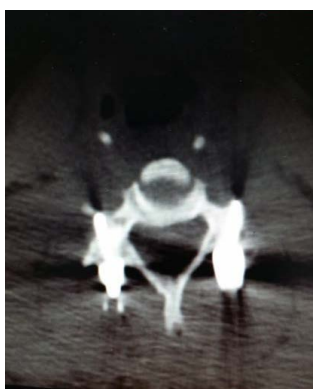

(b)

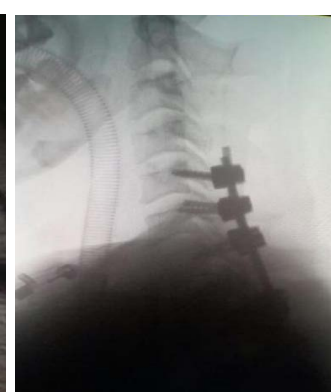

(c)

Figure 8. Post operative CT scan sagital (a), axial (b), and lateral X ray (c).

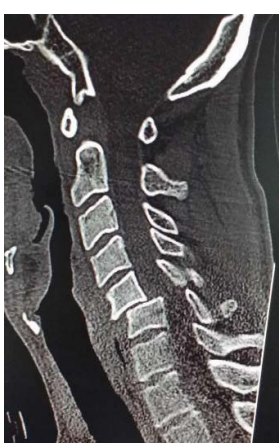

(a)

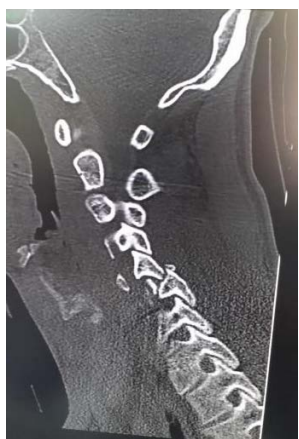

(b)

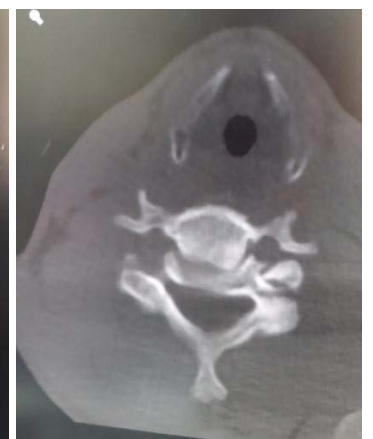

(c)

Figure 9. Pre operative CT spine sagittal (a), (b) and (c) views.

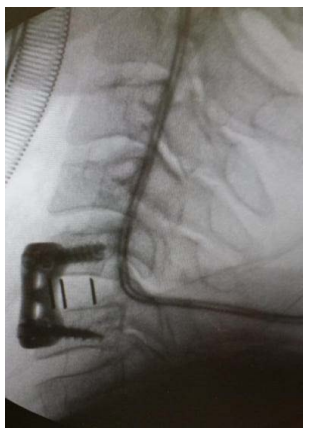

(a)

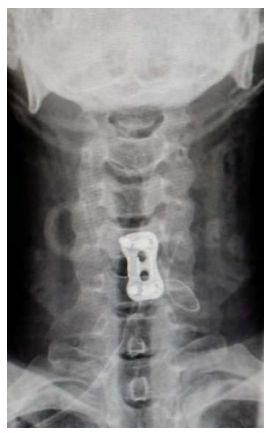

(b)

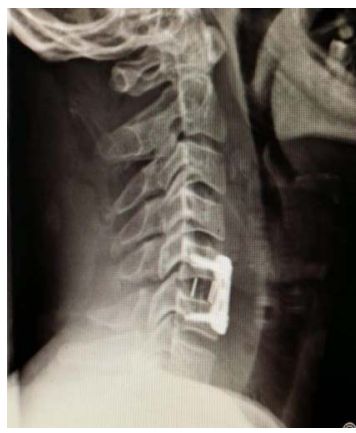

(c)

Figure 10. Intraoperative X ray lateral (a) and postoperative AP (b) and lateral (c). 
When closed reduction fails, open reduction is then indicated either by anterior or posterior approach, in anterior approach a standard cervical discectomy is performed. Thereafter, the posterior longitudinal ligament should be completely excised to facilitate the reduction of facets [19] [20]. After disk and posterior ligament resection, distractor pins are inserted and distractor placement results in local kyphosis, unlocking the posterior facet joints with some additional posterior force applied to the vertebral body. In unilateral dislocation, the pins are placed in a similar fashion but with additional coronal separation to open room for rotation. After distraction, which may release the facet joints, some gentle posterior force may be applied in the rostral vertebral body, reducing the locked joint and recovering articular congruence [21]. An alternative maneuver for reducing a locked facet joint is continuous intra operative external cranial traction. If the dislocation could not be reduced after an anterior approach, the patient must be turned prone with a direct partial facetectomy and reduction by gentle pulling the cranial spinous process cranially and the caudal one pulled caudally. The unilateral dislocations require a rotational pull along the direction of the locked facets. The procedure is continued till the reduction is complete, and inferior articular facet of the cranial vertebra is freed from the superior facet of the caudal vertebra. The affected segment then fixed by mean of lateral mass screws and rods to maintain reduction and stabilization [19] [21].

In our series there is a significant difference between VAS preoperatively and at final follow up in all cases. Mean preoperative pain score VAS was 7.7 (range from 5 to 9 ) and postoperative mean of VAS is 0.75 with (range from 0 to 3 ) until final follow up (Figure 3). Regarding the neurological status of the patients which is assessed by ASIA score all of the patients improved at least one level after surgery except 2 cases didn't improve they were score A pre-operative with bilateral locked facet.

The commonest level in our series is C6-7 (Figure 3). A combination of lower height, smaller anteroposterior diameter of the superior facet, and a more horizontally oriented superior facet at C6 and C7 levels in vivo may explain the predilection of this level for locked facet injury more than other levels [7].

The ASIA score was used as a guiding principle. Patients ranged from no sensory or motor function is preserved (score A) to normal sensory and motor function (score E). The cases with score A didn't improve post-operative and all these cases was ventilator dependent and associated with pulmonary complications (Table 1).

\section{Conclusion}

Trial of early skull traction-reduction should be performed for lower cervical locked facet dislocation, most of cases as our series successfully reduced especially bilateral locked facet and also percent of unilateral locked facet cases if there is successful reduction of facets. Anterior approach with discectomy and fusion is usually necessary, but if the closed reduction failed. Posterior open re- 
duction is highly indicated with lateral mass fixation. Combined approaches indicated in specific cases such as increase of the kyphotic angle post anterior approach or when an osteotomy may be required to restore cervical alignment and neural decompression. Patients with poor bone quality, such as those with osteoporosis, ankylosing spondylitis or other chronic conditions, may also be candidates for a combined approach.

\section{Conflicts of Interest}

The authors declare no conflicts of interest regarding the publication of this paper.

\section{References}

[1] Joaquim, A.F. and Patel, A.A. (2013) Subaxial Cervical Spine Trauma: Evaluation and Surgical Decision-Making. Global Spine Journal, 4, 63-70.

https://doi.org/10.1055/s-0033-1356764

[2] Shapiro, S.A. (1993) Management of Unilateral Locked Facet of the Cervical Spine. Neurosurgery, 33, 832-837. https://doi.org/10.1097/00006123-199311000-00007

[3] Dvorak, M.F., Fisher, C.G., Aarabi, B., et al. (2007) Clinical Outcomes of 90 Isolated Unilateral Facet Fractures, Subluxations, and Dislocations Treated Surgically and Nonoperatively. Spine, 32, 3007-3013. https://doi.org/10.1097/BRS.0b013e31815cd439

[4] Robertson, P.A. and Ryan, M.D. (1992) Neurological Deterioration after Reduction of Cervical Subluxation. Mechanical Compression by Disc Tissue. Journal of Bone and Joint Surgery, British Volume, 74, 224-227.

[5] Keynan, O., Dvorak, M. and Fisher, C. (2003) Reduction Techniques in Cervical Facet Dislocations. Techniques in Orthopaedics, 17, 336-344. https://doi.org/10.1097/00013611-200209000-00009

[6] Ludwig, S.C., Vaccaro, A.R., Balderston, R.A., et al. (1997) Immediate Quadriparesis after Manipulation for Bilateral Cervical Facet Subluxation. A Case Report. The Journal of Bone and Joint Surgery. American Volume, 79, 587. https://doi.org/10.2106/00004623-199704000-00017

[7] Ebrahim, N.A., Patil, V., Liu, J., Haman, S.P. and Yeasting, R.A. (2008) Morphometric Analysis of the Superior Facets and Implications for Facet Dislocation. International Orthopaedics, 32, 97-101. https://doi.org/10.1007/s00264-006-0286-5

[8] Lee Joon, Y., Ahmad, N., Eck, J.C. and Vaccaro, A.R. (2009) Controversies in the Treatment of Cervical Spine Dislocations. The Spine Journal, 9, 418-423.

https://doi.org/10.1016/j.spinee.2009.01.005

[9] Joaquim, A.F., Ghizoni, E., Tedeschi, H., Cruz, H.Y. and Patel, A.A. (2014) Clinical Results of Patients with Subaxial Cervical Spine Trauma Treated According to the SLIC Score. The Journal of Spinal Cord Medicine, 37, 420-424.

https://doi.org/10.1179/2045772313Y.0000000143

[10] Dvorak, M.F., Fisher, C.G., Fehlings, M.G., Rampersaud, Y.R., Oner, F.C., Aarabi, B., et al. (2007) The Surgical Approach to Subaxial Cervical Spine Injuries: An Evidence-Based Algorithm Based on the SLIC Classification System. Spine, 32, 2620-2629. https://doi.org/10.1097/BRS.0b013e318158ce16

[11] Ordonez, B.J., Benzel, E.C., Naderi, S. and Weller, S.J. (2000) Cervical Facet Dislocation: Techniques for Ventral Reduction and Stabilization. Journal of Neurosur- 
gery, 92, 18-23. https://doi.org/10.3171/spi.2000.92.1.0018

[12] Bartels, R.H. and Donk, R. (2002) Delayed Management of Traumatic Bilateral Cervical Facet Dislocation: Surgical Strategy: Report of Three Cases. Journal of Neurosurgery, 97, 362-365. https://doi.org/10.3171/spi.2002.97.3.0362

[13] Abumi, K., Shono, Y., Kotani, Y. and Kaneda, K. (2000) Indirect Posterior Reduction and Fusion of the Traumatic Herniated Disc by Using a Cervical Pedicle Screw System. Journal of Neurosurgery, 92, 30-37. https://doi.org/10.3171/spi.2000.92.1.0030

[14] Song, K.J. and Lee, K.B. (2008) Anterior versus Combined Anterior and Posterior Fixation/Fusion in the Treatment of Distraction-Flexion Injury in the Lower Cervical Spine. Journal of Clinical Neuroscience, 15, 36-42. https://doi.org/10.1016/j.jocn.2007.05.010

[15] Benzel, E.C. and Kesterson, L. (1989) Posterior Cervical Interspinous Compression Wiring and Fusion for Mid to Low Cervical Spinal Injuries. Journal of Neurosurgery, 70, 893-899. https://doi.org/10.3171/jns.1989.70.6.0893

[16] Levine, A.M., Mazel, C. and Roy-Camille, R. (1992) Management of Fracture Separations of the Articular Mass Using Posterior Cervical Plating. Spine, 17, S447-S454. https://doi.org/10.1097/00007632-199210001-00018

[17] Roy-Camille, R., Saillant, G., Laville, C. and Benazet, J.P. (1992) Treatment of Lower Cervical Spinal Injuries: C3 to C7. Spine, 17, S442- S446.

https://doi.org/10.1097/00007632-199210001-00017

[18] Crawford, N.R., Duggal, N., Chamberlain, R.H., Park, S.C., Sonntag, V.K. and Dickman, C.A. (2002) Unilateral Cervical Facet Dislocation: Injury Mechanism and Biomechanical Consequences. Spine, 27, 1858-1864. https://doi.org/10.1097/00007632-200209010-00010

[19] Wolf, A., Levi, L., Mirvis, S., et al. (1991) Operative Management of Bilateral Facet Dislocation. Journal of Neurosurgery, 75, 883-890. https://doi.org/10.3171/jns.1991.75.6.0883

[20] Rorabeck, C.H., Rock, M.G., Hawkins, R.J. and Bourne, R.B. (1987) Unilateral Facet Dislocation of the Cervical Spine. An Analysis of the Results of Treatment in $26 \mathrm{~Pa}$ tients. Spine, 12, 23-27. https://doi.org/10.1097/00007632-198701000-00004

[21] Fazl, M. and Pirouzmand, F. (2001) Intraoperative Reduction of Locked Facets in the Cervical Spine by Use of a Modified Interlaminar Spreader: Technical Note. Neurosurgery, 48, 444-445. https://doi.org/10.1227/00006123-200102000-00045 